Note

\title{
Alternative methodologies for sepiolite defibering
}

\author{
Leticia Lescano $^{\mathrm{a}, \mathrm{b}, *}$, Luciana Castillo ${ }^{\mathrm{c}, \mathrm{d}}$, Silvina Marfil ${ }^{\mathrm{a}, \mathrm{b}, 1}$, Silvia Barbosa $^{\mathrm{c}, \mathrm{d}}$, Pedro Maiza ${ }^{\mathrm{b}, \mathrm{c}, 1}$ \\ a Comisión de Investigaciones Científicas de la Provincia de Buenos Aires, (CIC), Argentina \\ ${ }^{\mathrm{b}}$ Universidad Nacional del Sur, Department of Geology, San Juan 670, 8000 Bahía Blanca, Provincia de Buenos Aires, Argentina \\ c CONICET, Bahía Blanca, Provincia de Buenos Aires, Argentina \\ d Universidad Nacional del Sur, PLAPIOUI (Planta Piloto de Ingeniería Química), Camino La Carrindanga Km. 7, 8000 Bahía Blanca, Provincia de Buenos Aires, Argentina
}

\section{A R T I C L E I N F O}

\section{Article history:}

Received 7 February 2012

Received in revised form 28 April 2014

Accepted 3 May 2014

Available online 20 May 2014

\section{Keywords:}

Sepiolite

Defibering

Acid treatment

Lyophilization

Purification

\begin{abstract}
A B S T R A C T
In this work, lyophilization and acid treatments were proposed as simple alternatives to defiber sepiolite samples, without affecting their length, in order to be applicable at industrial scale. Although it contains carbonates, the main remarkable feature of this clay mineral is its high crystalline development, reaching fiber lengths around $8 \mathrm{~cm}$. Proposed alternatives were analyzed comparatively, evaluating mainly the defibering effect. The influence of lyophilization and acid treatments on sepiolite structure and purity was qualitatively studied based on mineral characterization, electronic and optical microscopy, X-ray diffraction and Fourier transform infrared spectroscopy. Results show that acid treatment allowed sepiolite purification by removing carbonates as well as the reduction of fiber length. Lyophilization demonstrated to be an effective defibering process that allowed obtaining individualized fiber from bundle disaggregation, without affecting sepiolite length and flexibility.
\end{abstract}

(c) 2014 Elsevier B.V. All rights reserved.

\section{Introduction}

Clays and clay minerals have demonstrated to be interesting materials due to their high adsorption capability, colloidal properties as well as the possibility of tailoring their surface characteristics to provide specific solutions for a wide variety of industrial applications (Jones and Galán, 1988). Since clays are very abundant and naturally occurring, they are relatively cheap and environmentally friendly materials with good properties, which makes them very attractive in the academic and industrial field.

Nowadays, sepiolite is a clay mineral used in a wide range of technological applications. Due to its fibrous morphology and surface characteristics, it is considered an excellent reinforcement in polymer-based nanocomposites (Bokobza et al., 2004; Ruiz-Hitzky et al., 2013). In addition, its peculiar characteristics are also useful in photocatalysis (Aranda et al., 2008), heavy metals adsorption (Dogan et al., 2008), metallic nanoparticle support with biocide (Cubillo et al., 2006) or plasmonic properties (Pecharromán et al., 2009), as well as vaccine support (Pecharromán et al., 2009), and electronic conductors (Gómez-Avilés et al., 2007). Each structural block is composed by two-dimensional tetrahedral silica sheet and a central magnesium octahedral one. Tetrahedral sheets are inverted every six units, determining a regular

\footnotetext{
* Corresponding author at: Universidad Nacional del Sur, Department of Geology, San Juan 670, second floor, 8000 Bahía Blanca, Provincia de Buenos Aires, Argentina. Tel.: + $542914595101 \times 3021$.

E-mail address: leticia.lescano@uns.edu.ar (L. Lescano).

1 Tel.: + $542914595101 \times 3021$
}

discontinuity of the octahedral sheets and inducing a ribbon pattern. This periodic inversion favors the formation of rectangular channels (parallel to the fiber length) and the presence of silanol groups ( $\mathrm{SiOH})$. Along these channels, coordination and charge balance are completed by protons, coordinated water, and a small number of exchangeable cations. The high density of silanol groups at sepiolite surface are the major responsible for its outstanding properties because they are easily available for coupling reactions with organic surfactants and polymers. Moreover, these groups allow developing forces such as hydrogen bonding and Van der Waals interactions which are largely involved in the adsorption phenomena (Brigatti et al., 2013).

Any attempt to obtain individualized fibers from natural sepiolite micrometric aggregates would profit the development of technological applications, taking advantage of the silanol-based chemistry and the nanometric diameter of isolated fibers. For this reason, it is necessary to propose a defibering method which would be efficient and relatively simple, without affecting fiber length. Particularly, sepiolite from La Adela mine (Argentina), which was firstly described by Cortelezzi et al. (1994), shows a peculiar feature related to its high crystalline development. However, this clay mineral is emplaced within dolomitic rock bodies, which are responsible for the presence of impurities.

In this work, lyophilization and acid treatments were analyzed comparatively evaluating mainly the defibering effect on high crystalline sepiolite from La Adela ore (Argentina) and their purification, in order to be applicable at industrial scale. For this purpose, treatment effect on sepiolite structure and purity was studied based on mineral characterization, electronic and optical microscopy, X-ray diffraction and Fourier transform infrared spectroscopy. Taking into account that $\mathrm{La}$ 
Adela mine is not commercially exploited, defibering and purifying of sepiolite samples through any of the proposed methods is an interesting tool to add value to this clay mineral.

\section{Materials and methods}

Sepiolite from La Adela mine (province of Río Negro, Argentina) occurs as white fibrous aggregates within veins, being a flexible and soft mineral with low hardness (2-2.5). Sepiolite samples present a remarkable crystalline growth with fiber length reaching up to $8 \mathrm{~cm}$. Since this clay mineral is developed between joints and bedding planes of a dolomitic rock, sepiolite samples contain impurities, mainly carbonates (dolomite and calcite). In this work, lyophilization and acid treatments were proposed as two different methodologies for sepiolite defibering.

\subsection{Lyophilization}

This method consists of a dehydration process under vacuum, where water evaporation is produced by ice sublimation. Approximately $1 \mathrm{~g}$ of sepiolite was introduced in a lyophilizer at $-50{ }^{\circ} \mathrm{C}$ Rificor with a vacuum of $0.009 \mathrm{mmHg}$ for $50 \mathrm{~h}$.

\subsection{Acid treatment}

Sepiolite ( $1 \mathrm{~g}$ ) was contacted with $100 \mathrm{ml}$ of acid for $2 \mathrm{~h}$ with constant magnetic stirring at $80{ }^{\circ} \mathrm{C}$. For this treatment, hydrochloric acid $(\mathrm{HCl}) 1.6 \mathrm{M}$ and acetic acid $\left(\mathrm{CH}_{3} \mathrm{COOH}\right) 17.5 \mathrm{M}$ were used. After treatment, sepiolite fibers were washed repeatedly with distilled water to remove residual acid and then were filtered. Samples were dried in a vacuum oven at $70{ }^{\circ} \mathrm{C}$ for $48 \mathrm{~h}$, up to constant weight.

\subsection{Mineralogical characterization}

The petrographic study by polarized light microscopy (PLM) was carried out on thin sections of rock samples obtained in fractures of the dolomitic rock. To perform this analysis an Olympus SZ-Pt trinocular stereomicroscope and an Olympus B2-UMA trinocular petrographic microscope were used. Both of them are equipped with a built-in videocamera, a digital capture system and a software for image processing. In order to confirm the presence of carbonates in sepiolite samples, thermogravimetric analysis (TGA) was carried out in a TA thermoanalytical equipment (model SDT Q600) by heating from 30 to $1000{ }^{\circ} \mathrm{C}$ at $10{ }^{\circ} \mathrm{C} / \mathrm{min}$, under nitrogen atmosphere. Thermogravimetric (TG), derivative thermogravimetric (DTG) and differential thermal analysis (DTA) curves were recorded.
Initial and treated sepiolite fiber was structurally characterized by several techniques. Morphological analysis of fibrous samples was carried out by scanning electron microscopy (SEM) in a JEOL $35 \mathrm{CF}$ instrument. X-ray Diffraction (XRD) was used to identify crystalline structures and crystallinity changes induced by the proposed treatment on sepiolite fibers. Diffraction patterns were obtained in a Rigaku D-Max III-C diffractometer, working at $35 \mathrm{kV}$ and $15 \mathrm{~mA}$, using $\mathrm{Cu} \mathrm{K \alpha _{1,2 }}$ radiation $(\mathrm{K}=1.541840 \AA$ ) filtered with a graphite monochromator in the diffracted-beam, between 3 and $60^{\circ} 2 \theta$. The $2 \theta$ values ranged from $3^{\circ}$ to $60^{\circ}$. Chemical bonds were determined by Fourier Transform Infrared Spectroscopy (FTIR) using a Nicolet 520 spectrophotometer. Spectra were obtained in the range from 400 to $4000 \mathrm{~cm}^{-1}$, running 100 scans at a resolution of $4 \mathrm{~cm}^{-1}$. Samples were diluted at $2 \mathrm{wt}$.\% in potassium bromide $(\mathrm{KBr})$.

\section{Results}

\subsection{Mineralogical characterization of sepiolite samples}

Mineralogical characterization of natural sepiolite was introduced in order to identify the presence of impurities and their distribution. From petrographic study, it was evidenced that sample color turned into colorless and gray, revealing a low relieve ( $\mathrm{n}<$ balsam) and a relatively strong birefringence. In addition, extinction was approximately parallel with positive elongation (length-slow). Polarized photomicrograph of thin section from sample rock in contact with dolomitic body is presented in Fig. 1a. Sepiolite fibers demonstrated a high flexibility and elongation parallel to pre-existing fractures, as it is expected because of their high diameter to length ratio. The size of these fibers in some cases exceeded the microscope magnification. The presence of carbonates (dolomite (D) and calcite (C)) is indicated in Fig. 1a. Calcite vein, having a width of $250 \mu \mathrm{m}$, was extended along the contact between the dolomitic rock and sepiolite. These veins were developed together with the sepiolite and after dolomite formation. It is possible to recognize two different carbonate generations, the first one corresponding to the original rock with an important crystalline development; and the second one, having smaller crystals in veins. Thermogravimetric analysis was used to confirm the presence of carbonate in sepiolite samples (Fig. 1b). Four irreversible endothermic reactions, corresponding to weight loss steps, were detected in TG curve, in good accordance with previous works (Frost and Ding, 2003; Tartaglione et al., 2008). In the low temperature region, endothermic reactions testified the loss of adsorbed and zeolitic water (peak upwards around $68{ }^{\circ} \mathrm{C}$ in DTG curve). The release of coordinated water molecules linked to $\mathrm{Mg}^{2+}$ ions was detected between $180{ }^{\circ} \mathrm{C}$ and $350{ }^{\circ} \mathrm{C}$. As temperature increased, carbonate
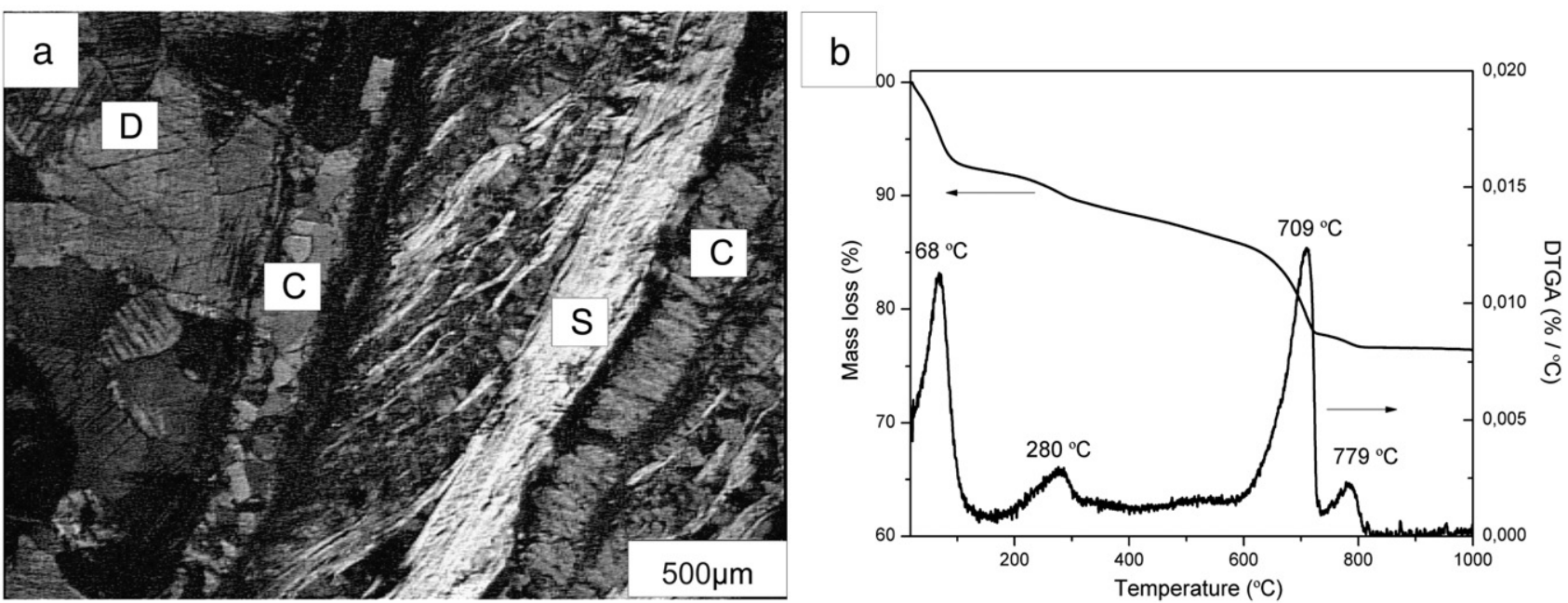

Fig. 1. a) Polarized microscopy on thin sections between calcite and fibrous sepiolite wall rock (without crossed nicols), and b) TG, DTG and DTA curves of sepiolite samples. 

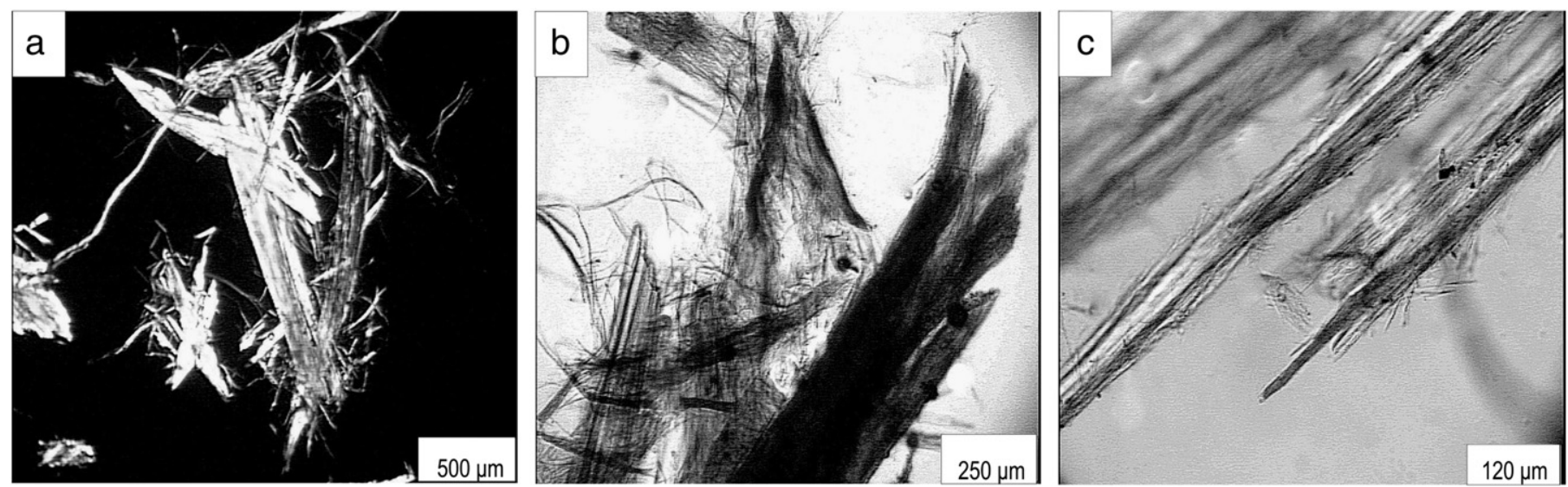

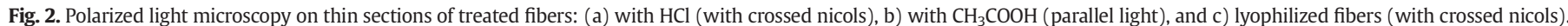

decomposition was observed at $709{ }^{\circ} \mathrm{C}$. In the high temperature region $\left(>750{ }^{\circ} \mathrm{C}\right)$, sepiolite dehydroxylation occurred, being identified by the peak at $779{ }^{\circ} \mathrm{C}$ in DTG curve. This step involved the phase transformation of sepiolite into enstatite $\left(\mathrm{MgSiO}_{3}\right)$. No further weight loss was observed at higher temperatures. The global weight loss, related to the release of bound water and hydroxyls as well as carbonate decomposition was $23.6 \%$ under the studied conditions. DTA curve showed an endothermic peak at $67{ }^{\circ} \mathrm{C}$ due to the loss of water adsorbed on the outer surfaces and from the channels. At higher temperatures, there was a very marked and broader endothermic peak at $780{ }^{\circ} \mathrm{C}$, associated to the release of octahedral $\mathrm{OH}$ and probably those from $\mathrm{SiOH}$ groups. In addition, this peak could be associated to calcite and dolomite decomposition taking into their degradation temperature are comprised within this range. An exothermic peak was detected at $801-830{ }^{\circ} \mathrm{C}$ which is related to the formation of enstatite $\left(\mathrm{MgSiO}_{3}\right)$ (Pérez-Rodríguez and Galán, 1994).

\subsection{Effect of proposed treatments on sepiolite structure and purity degree}

In order to study the structural changes induced by acid treatments and lyophilization, natural and treated fibers were characterized by a combination of PLM, SEM, XRD and FTIR. Polarized light photomicrographs corresponding to treated fibers are presented in Fig. 2. Acid treatment with $\mathrm{HCl}$ reduced significantly sepiolite length and disintegrated fibers bundles into smaller entities (Fig. 2a). Flexibility
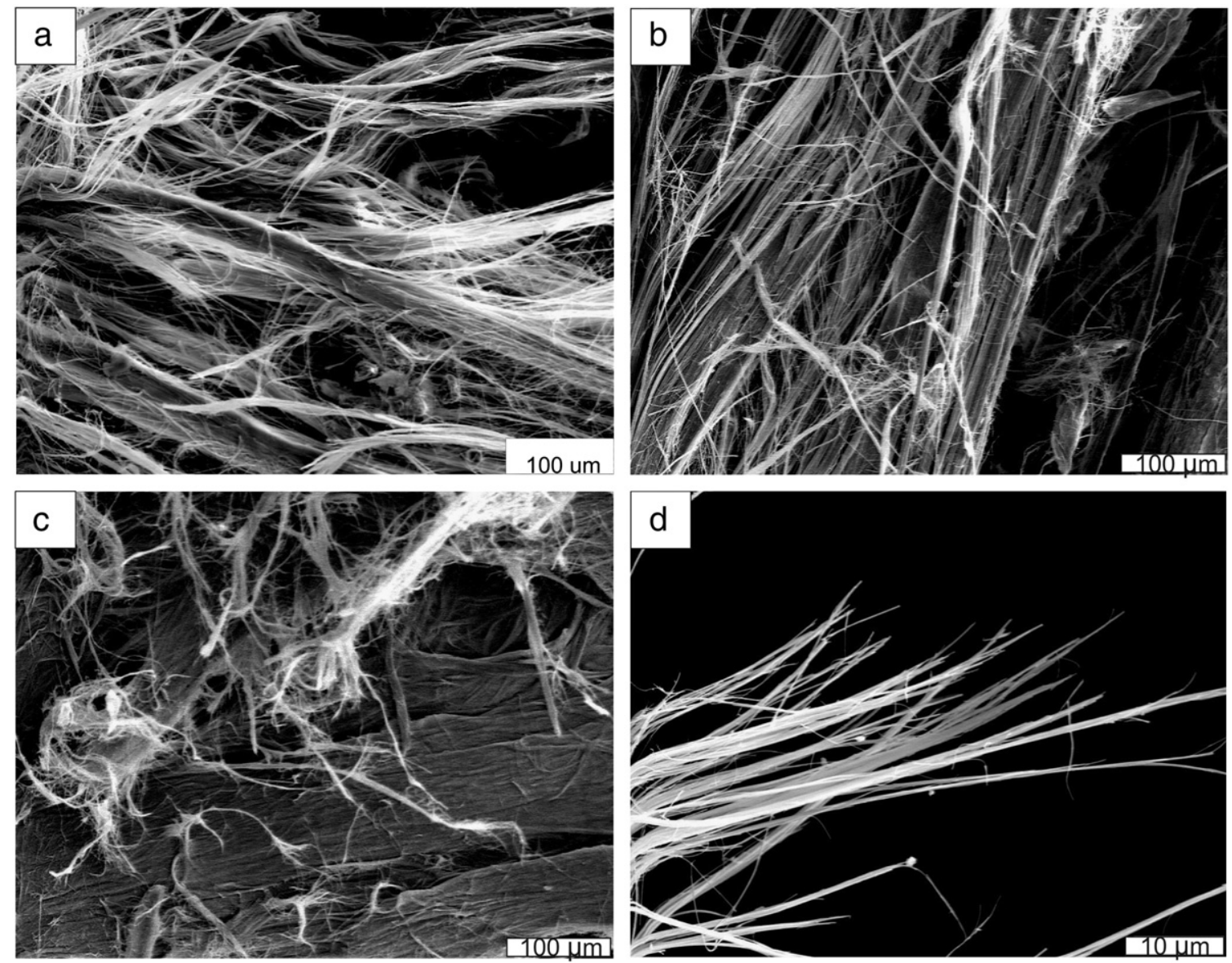

Fig. 3. SEM micrograph of sepiolite: (a) natural, (b) treated with $\mathrm{HCl}$, (c) treated with $\mathrm{CH}_{3} \mathrm{COOH} \mathrm{HCl}$ and (d) lyophilized. 
and natural entanglement were more evident in smaller fibers. Treated fibers with $\mathrm{CH}_{3} \mathrm{COOH}$ did not affect strongly the fiber length, but an incipient defibering was observed (Fig. 2b). In addition, small carbonate crystals were detected. In contrast with acid treatment results, lyophilization allowed fiber disaggregation as almost individualized units which conserved their initial length (Fig. 2c). They were long, thin and elastic, different from their natural morphology, where are tightly compressed.

The effect of acid treatments and lyophilization on sepiolite morphology was observed by SEM (Fig. 3). Fibrous habit and flexibility of natural fiber could be distinguished in Fig. 3a. This typical sepiolite morphology, agglomerated in dense bundles, contained carbonate crystals which were identified in SEM micrograph. Fibers treated with $\mathrm{HCl}$ revealed a disaggregated morphology, evidenced by the tip opening of sepiolite bundles (Fig. 3b). Acid treatment using $\mathrm{CH}_{3} \mathrm{COOH}$ allowed fiber separation from bundles, inducing an incipient defibering (Fig. 3c). Lyophilized sepiolite showed noticeable morphological changes with respect to the acid treatments (Fig. 3d). Fibers are totally separated from each other as a result of an effective bundle opening, without affecting their length and flexibility. Lyophilization method allowed defibering as a result of water freezing and sublimation in sepiolite channels, creating less dense "packages".

Natural sepiolite XRD spectra and those corresponding to treated samples are compared in Fig. 4. Diffractogram of natural sepiolite showed main reflections at $12.1,4.5$ and 3.37 Á which were comparable to those included in ICDD 13-595 (ICDD, 1993). This clay mineral has a significant crystallinity, revealed by the maximum intensity peak. In addition, carbonates were detected by XRD, confirming crystals' presence in SEM micrograph. Dolomite was detected by the peak at $2.88 \AA$, meanwhile calcite reflections were observed at 2.40 and $1.85 \AA$ A. After treatment with $\mathrm{HCl}$, sepiolite reflection intensities decreased in comparison with those of natural sample. In addition, dolomite and calcite peaks were not detected. This acid treatment allowed carbonate solubilization, but reduced sepiolite crystallinity,

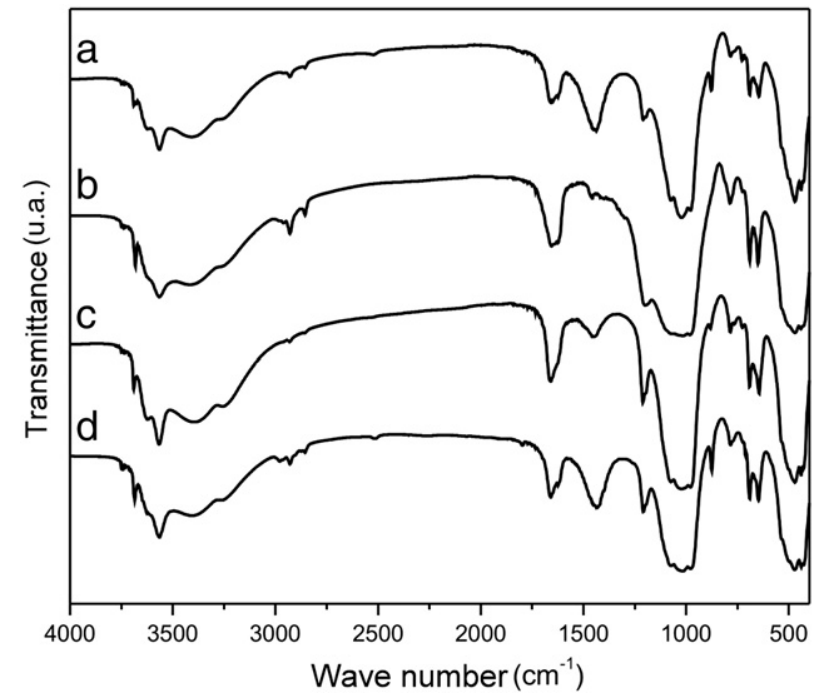

Fig. 5. FTIR spectra of natural and treated samples.

according to a previous work (Turhan et al., 2008). Diffractogram of sepiolite treated with $\mathrm{CH}_{3} \mathrm{COOH}$ showed a good crystallinity, being comparable to the corresponding natural sample. Dolomite and calcite peaks were present due to the aggressiveness of this acid treatment which was not strong enough to eliminate carbonates completely. In the lyophilized sepiolite spectrum, no structural and crystallinity changes were recognized. Despite the fact that dolomite was not detected, calcite traces were observed.

The influence of proposed treatments on sepiolite purification was also studied by FTIR (Fig. 5). Table 1 presents band assignment corresponding to natural fiber spectrum (Fig. 5a). Despite acid treatments with $\mathrm{HCl}$ and $\mathrm{CH}_{3} \mathrm{COOH}$, it allowed to decrease bands' intensity located
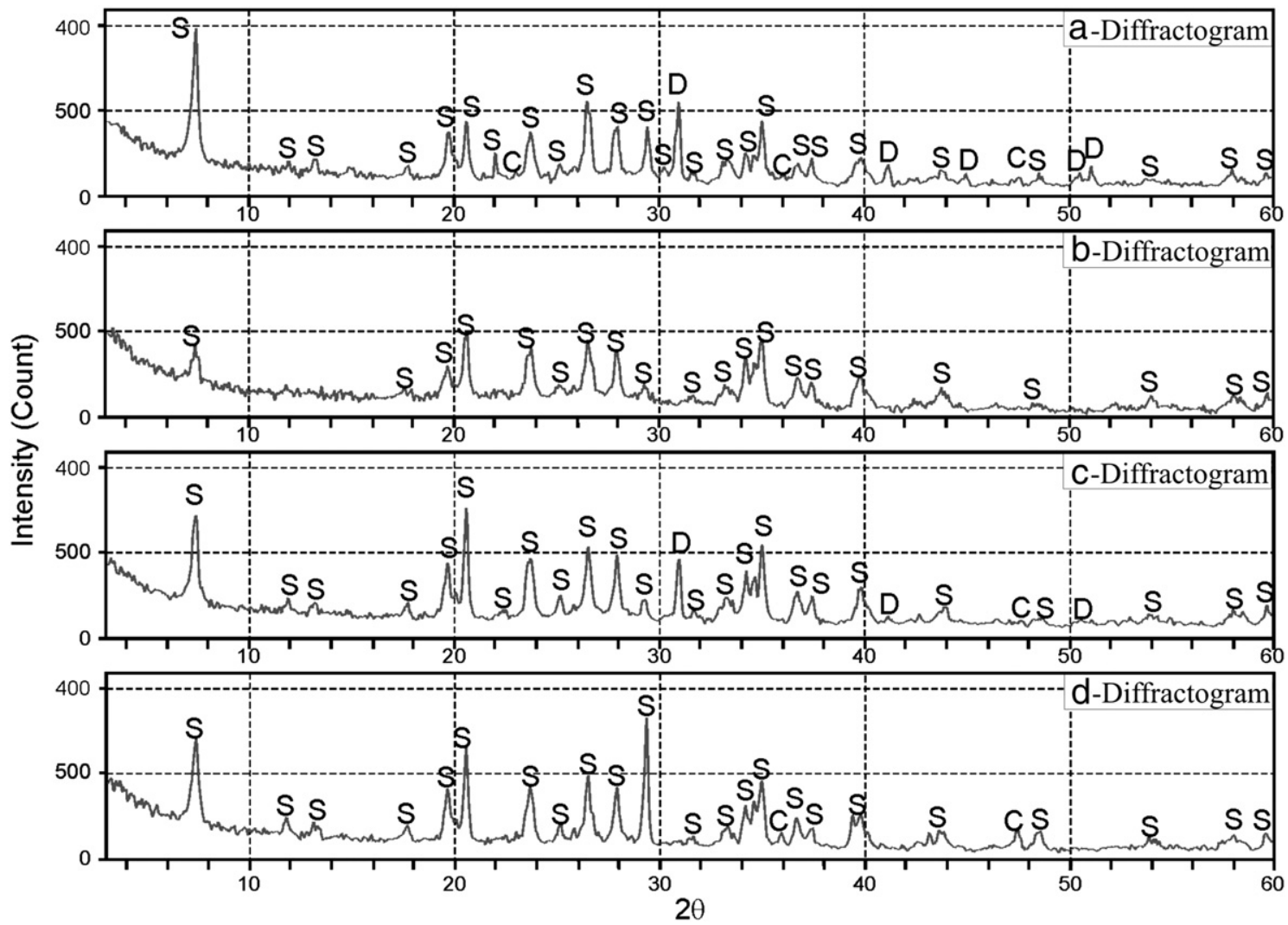

Fig. 4. X-ray diffraction of natural and treated samples. (Ref: $\mathrm{S}=$ sepiolite, $\mathrm{D}=$ dolomite, $\mathrm{C}=$ calcite). 
Table 1

Assignment of detected bands for natural sepiolite.

\begin{tabular}{|c|c|}
\hline Wavenumber $\left(\mathrm{cm}^{-1}\right)$ & Assignment \\
\hline 3688 y 3565 & $\begin{array}{l}\text { Stretching of } \mathrm{OH} \text { groups (belonging to } \mathrm{Mg}_{3} \mathrm{OH} \text { ) } \\
\text { linked to } \mathrm{Mg}^{2+} \text { ions }\end{array}$ \\
\hline 618 & $\begin{array}{l}\mathrm{H}-\mathrm{O}-\mathrm{H} \text { stretching of water molecules weakly } \\
\text { linked to } \mathrm{Si}-\mathrm{O}\end{array}$ \\
\hline 3408 & $\mathrm{H}-\mathrm{O}-\mathrm{H}$ vibrations of adsorbed water \\
\hline 2929 у 2856 & Secondary contamination \\
\hline 522,1437 y 877 & Calcite \\
\hline 1657 & Deformation of $\mathrm{OH}$ group of water \\
\hline 1209, 1073 у 979 & $\mathrm{Si}-\mathrm{O}$ vibration of tetrahedrical sheet \\
\hline 1021 & $\mathrm{Si}-\mathrm{O}$ and $\mathrm{Si}-\mathrm{O}-\mathrm{Si}$ stretching of tetrahedrical sheet \\
\hline 784 & Secondary quartz \\
\hline 728 & Dolomite \\
\hline 691 & $\mathrm{Mg}_{3} \mathrm{OH}$ bending vibration \\
\hline 645 & $\begin{array}{l}\text { Bending vibration of } \mathrm{OH} \text { groups bonded to octahedrical } \\
\mathrm{Mg}^{2+} \text { ions }\end{array}$ \\
\hline 470 & Bending vibration of $\mathrm{Si}-\mathrm{O}$ \\
\hline 440 & $\mathrm{Si}-\mathrm{O}-\mathrm{Mg}$ vibration \\
\hline
\end{tabular}

at 2522, 1437 and $877 \mathrm{~cm}^{-1}$, which are related to carbonates' presence, and higher efficiency on purification was achieved by using $\mathrm{HCl}$. In the lyophilized sample spectrum, carbonates and secondary contamination bands were detected.

\section{Conclusions}

Acid treatments and lyophilization were proposed as a relatively simple alternative for defibering sepiolite bundles and, eventually, for purification in order to be used at industrial scale. Clay mineral samples came from La Adela mine, which is a deposit not commercially exploited that presents peculiar morphological characteristics related to its high crystalline development.

Acid treatments allowed sepiolite purification by removing carbonates. This method allowed the conservation of clay mineral structure, and fiber crystallinity was sensitively reduced. In addition, a significant reduction in fiber length was detected. Despite that purification was effective, the fact that crystallinity decreased and fiber length was strongly reduced makes it not proper to defiber sepiolite samples by acid treatments.

Lyophilization demonstrated to be an effective defibering process that allowed the obtaining of individualized fiber from bundle disaggregation, without affecting sepiolite length and flexibility. The efficiency of this method resides on the fact that freezing of water within sepiolite channels causes a volume increase that induces fiber separation when ice sublimates. Despite that purification effect by lyophilization was not completely effective, this method was the most favorable to obtain individualized fibers preserving its highs crystalline development.

\section{References}

Aranda, P., Kun, R., Martín-Luengo, A., Letaïef, S., Dekany, I., Ruiz-Hitzky, E., 2008. Titaniasepiolite nanocomposites prepared by a surfactant templating colloidal route. Chem. Mater. 20, 84-91.

Bokobza, L., Burr, A., Garnaud, G., Perrin, M.Y., Pagnotta, S., 2004. Fibre reinforcement of elastomers: nanocomposites based on sepiolite and poly(hydroxyethyl acrylate). Polym. Int. 53, 1060-1065.

Brigatti, M.F., Galán, E., Theng, B.K.G., 2013. Structure and mineralogy of clay minerals. In: Bergaya, F., Lagaly, G. (Eds.), The Handbook of Clay Science. Elsevier, United Kingdom, pp. 21-81.

Cortelezzi, C.R., Marfil, S.A., Maiza, P.J., 1994. A sepiolite of large crystalline growth from "La Adela" mine province of Río Negro, Argentina. Neues Jahrb. Mineral. Monatshefte 157-166 (Stuttgart).

Cubillo, E.A., Pecharromán, C., Aguilar, E., Santarén, J., Moya, J.S., 2006. Antibacterial activity of copper monodispersed nanoparticles into sepiolite. J. Mater. Sci. 41 5208-5212.

Dogan, M., Turhan, Y., Alkan, M., Namli, H., Turan, P., Demirbas, O., 2008. Functionalized sepiolite for heavy metal ions adsorption. Desalination 230 (1-3), 248-268.

Frost, R.L., Ding, Z., 2003. Controlled rate thermal analysis and differential scanning calorimetry of sepiolites and palygorskites. Thermochim. Acta 397, 119-128.

Gómez-Avilés, A., Darder, M., Aranda, P., Ruiz-Hitzky, E., 2007. Functionalized carbonsilicates from caramel-sepiolite nanocomposites. Angew. Chem. Int. Ed. 46, 923-925.

International Centre for diffraction Data (ICDD), 1993. Mineral Powder Diffraction File Databook. (1-42: 614-615), Swarthmore, Pennsylvania, U.S.A. pp. 614-615.

Jones, B.F., Galán, E., 1988. Sepiolite and palygorskite. In: Bailey, S.W. (Ed.), Hydrous Phyllosilicates. Reviews in Mineralogy, vol. 19. Min. Soc. Amer., Washington, pp. 631-674.

Pecharromán, C., Esteban-Cubillo, A., Montero, I., Moya, J.S., Aguilar, E., Santarén, J., RuizHitzky, E., Darder, M., Aranda, P., Martín del Burgo, M.A., del Real, G., 2009. Bionanocomposites as new carriers for Influenza vaccines. Adv. Mater. 21, 4167-4171.

Pérez-Rodríguez, J., Galán, E., 1994. Determination of impurity in sepiolite by thermal analysis. J. Therm. Anal. 42, 131-141.

Ruiz-Hitzky, E., Aranda, P., Darder, M., Fernandes, F.M., 2013. Fibrous clay mineral polymer nanocomposites. In: Bergaya, F., Lagaly, G. (Eds.), The Handbook of Clay Science. Elsevier, United Kingdom, pp. 721-741.

Tartaglione, G., Tabuani, D., Camino, G., 2008. Thermal and morphological characterization of organically modified sepiolite. Microporous Mesoporous Mater. 107, 161-168.

Turhan, Y., Turan, P., Dogan, M., Alkan, M., Namli, H., Demirbas, O., 2008. Characterization and adsorption properties of chemically modified sepiolite. Ind. Eng. Chem. Res. 47, 1883-1895. 